\title{
Comparison of the prevalence of reversible airways obstruction in rural and urban Zimbabwean children
}

\author{
D J Keeley, P Neill, S Gallivan
}

\begin{abstract}
The prevalence of reversible airways obstruction has been assessed in children in three areas in Zimbabwe-northern Harare (high socioeconomic class urban children), southern Harare (low socioeconomic class urban children), and Wedza Communal Land (rural children from peasant families). Peak expiratory flow (PEF) was measured before and after six minutes' free running in 2055 Zimbabwean primary school children aged 7-9 years. Height and weight were measured and nutritional state expressed as a percentage of the 50 th centile for age (Tanner-Whitehouse standards). Reversible airways obstruction was deemed to be present when peak expiratory flow was below the $2 \cdot 5$ th centile for height before exercise and rose by more than $15 \%$ after inhalation of salbutamol and when it fell by $15 \%$ or more after exercise and rose again after salbutamol. The prevalence of reversible airways obstruction was $5 \cdot 8 \%$ (95\% confidence interval $4 \cdot 1-7 \cdot 5 \%$ ) in northern Harare $(n=726) ; 3.1 \%(1.8-4.5 \%)$ in southern Harare $(n=642)$, and $0.1 \%$ $(0.0-0.4 \%)$ in Wedza $(n=687)$. In northern Harare, the only study area in which white children were found, the prevalence of reversible airways obstruction was similar in white $(5 \cdot 3 \%, 10 / 188)$ and black $(5.9 \%, 32 / 538)$ children. Indicators of nutritional state also showed no significant differences between white and black children in northern Harare but were lower in southern Harare and lower still in Wedza. Urban living and higher material standards of living appear to be associated with a higher prevalence of reversible airways obstruction in children in Zimbabwe.
\end{abstract}

Childhood asthma is an extremely common problem in industrialised countries and there is evidence that the prevalence may have increased in the last 20 years. ${ }^{1-5}$ Studies from the developing world have shown large variations in asthma prevalence in genetically similar populations living in different environments. ${ }^{6-8}$ Both lines of evidence suggest that the major determinants of asthma prevalence in any particular population are environmental. Knowledge of different prevalence rates in differing environments should help to guide the design of further studies in an attempt to identify which factors in the environment are relevant to the development of asthma in genetically predisposed individuals.

The epidemiological study of asthma is beset by problems of definition, ${ }^{9}$ and comparison of the results of the various studies is made difficult by differences between the methods of data collection. The measurement of change in peak expiratory flow (PEF) in a free running exercise challenge test, however, is a sensitive method of screening for bronchial hyperreactivity in children ${ }^{10}$ and can easily be used to screen large numbers of children. ${ }^{711}$ Careful adherence to method within a particular study allows confidence in the significance of differences between groups:

The study of Van Niekerk and others ${ }^{7}$ in South Africa showed the prevalence of exercise induced bronchoconstriction in Xhosa children to be 20 times higher in an urban setting than in a rural setting. Paediatricians in Zimbabwe find that asthma is very rare in rural children but not uncommon in towns. We decided to compare the prevalence of reversible airways obstruction in primary school children in three different settings-a rich urban, a poor urban, and a rural area. The existence of a sufficient number of white children in the rich urban setting allowed us to compare the prevalence in the two different racial groups in that setting.

\section{Methods}

The study was conducted during three weeks in March 1988. March is towards the end of the rainy season and is a time of relatively high incidence of asthma attacks in Zimbabwe. ${ }^{12} \mathrm{We}$ studied 2055 primary school children in grades 2 and 3 (age 7-9 years).

\section{THE STUDY AREAS}

There were three study areas: northern Harare, southern Harare, and Wedza. Harare, the capital of Zimbabwe, is situated $1529 \mathrm{~m}$ above sea level. Northern Harare consists of low density housing of generally high quality and children in northern Harare schools come in the main from relatively high income families. In southern Harare we went to schools in high density suburbs occupied largely by low income families. Wedza is a rural communal land district $150 \mathrm{~km}$ south east of Harare at a similar altitude $(1650 \mathrm{~m})$. Children in the Wedza schools were nearly all from peasant families. Four schools were visited in northern Harare, three in southern Harare, and six in Wedza. 
During the month of the study at 1100 hours the mean temperature was $23.6^{\circ} \mathrm{C}$ in Harare and $21.7^{\circ} \mathrm{C}$ in Wedza, and the mean relative humidity was $67 \%$ in Harare and $72 \%$ in Wedza (data from the Meteorological Office, Harare).

\section{THE CHILDREN}

In the northern Harare schools there were 188 white children among the 726 children studied. The few Asian and mixed race children at these schools were not included in the analysis. In southern Harare and Wedza all children were black.

The issue of parental consent was left to the headmasters' discretion. It was thought to be necessary only by the headmasters of three of the four northern Harare schools. In these schools parents' consent was sought by a letter that asked, if permission was withheld, whether this was because the child had been diagnosed as having asthma or for another reason. Children refused permission to participate were excluded from the analysis. Also excluded were eight children considered either by the teacher or by us to be unfit for running; the reasons included cyanotic congenital heart disease, acute mumps, and an arm in plaster.

\section{PROTOCOL}

Complete classes were studied, class teachers having listed the names and dates of birth of the children in their class from the register. Any absentees were noted and schools were revisited to study returned absentees or to gather information from child or teacher about the reason for absence.

Children were brought out a class at a time and each child was weighed and measured. For each child height and weight were subsequently expressed as percentages of the 50th centile for age, the Cole Slide-Rule incorporating the Tanner-Whitehouse standards being used.

The use of the Wright peak flow meter was demonstrated to the whole class. Pre-exercise peak flow was recorded for each child; if the child did not have a satisfactory technique and make a maximal effort by the third blow an individual demonstration of the technique was given before three further blows were measured. The highest value achieved was recorded. Only 10 children were unable to achieve an apparently satisfactory technique and they were excluded from the analysis.

Any child whose peak flow was below the 2.5 th centile for height (the lowest line on the nomogram derived from original data of Godfrey et $a l^{13}$ ) before running was given salbutamol $400 \mu \mathrm{g}$ by metered dose inhaler through a Volumatic spacer device. Peak flow was measured again after five and 10 minutes and the higher value recorded. Children whose peak flow rose by over $15 \%$ were categorised as having reversible airways obstruction. All these children were allowed to join in the running, whether or not the peak flow had risen with salbutamol.

The children ran up and down the length of the school football pitch for six minutes. They ran in groups of four, setting off at two minute intervals. Peak flow was measured again five minutes after the run finished. If a fall greater than $15 \%$ of the pre-exercise value had occurred peak flow was measured again three minutes later. If the peak flow then remained more than $15 \%$ below the resting value the child was categorised as having exercise induced bronchoconstriction. These children were given salbutamol $400 \mu \mathrm{g}$ by metered dose inhaler through the Volumatic spacer, which invariably resulted in a rise of PEF to near or above the pre-exercise level.

Seven children failed to complete the run. Peak flow was nevertheless measured five minutes later; none of these children showed any appreciable fall in peak flow and they were excluded from the analysis.

All children who had required salbutamol were re-examined before returning to the classroom. No child required further treatment. No child other than those identified by a fall in peak flow five minutes after exercise developed obvious dyspnoea requiring bronchodilator treatment.

The entire study was conducted by the same four investigators, consistency of method thus being ensured. All children were studied during the hours 0900-1200 to minimise any possible effect of diurnal variation in airway responsiveness on the results.

The study was approved by the ethical committee of the Harare group of hospitals.

\section{ANALYSIS}

Statistical analysis was carried out by using the computer package Minitab $^{14}$ on an IBM compatible personal computer. Calculation of $95 \%$ confidence intervals for population proportions was carried out by the methods described by Armitage and Berry. ${ }^{15}$

\section{Results}

The prevalence of reversible airways obstruction in the three study groups was $5.8 \%$ $(42 / 726)$ in northern Harare $(95 \%$ confidence interval $4 \cdot 1-7 \cdot 5 \%), 3 \cdot 1 \%(20 / 642)$ in southern Harare $(1 \cdot 8-4.5 \%)$, and $0 \cdot 1 \%(1 / 687)$ in Wedza $(0.0-0.4 \%)-$ see figure 1 . Thus the prevalence was significantly lower in southern Harare than in northern Harare, and very much lower still in rural Wedza, where only one out of 687 children had reversible airways obstruction. Evidence of reversible airways obstruction was present before the running in 15/42 children in northern Harare, in $6 / 20$ in southern Harare, and in none in Wedza.

In 12 children peak flow was below the $2 \cdot 5$ th percentile for height but failed to rise with salbutamol (three in northern Harare, four in southern Harare, and five in Wedza). These children took part in the running; none then showed any reduction in peak flow and they were counted as normal.

In northern Harare the prevalences of reversible airways obstruction in white children $(10 / 188,5.3 \%)$ and black children $(32 / 538$, $5.9 \%$ ) showed no significant difference.

Among children with evidence of reversible airways obstruction a male preponderance was 
Figure 1 Prevalence of reversible airways from North Harare $(n=$ $726)$, South Harare $(n=$ 642), and Wedza ( $n=$ 687), with $95 \%$ confidence intervals. obstruction in the children

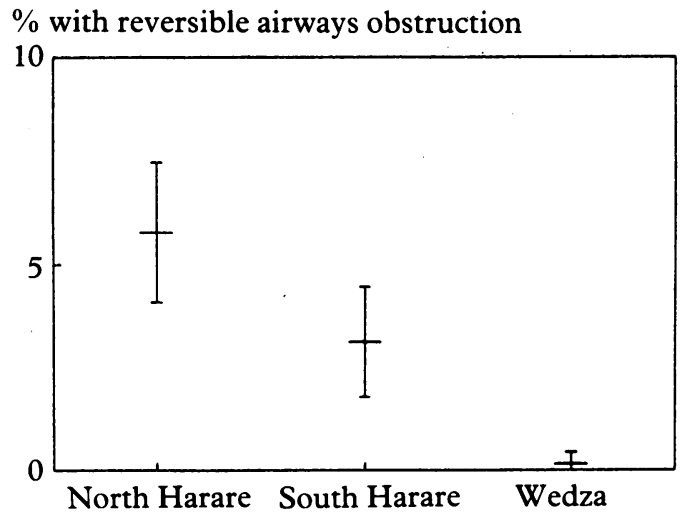

Figure 2 Nutritional state (mean percentages of 50th centile height and weight for age with $95 \%$ confidence limits) of the children from North Harare $(n=726)$, South Harare $(n=642)$, and Wedza $(n=687)$.

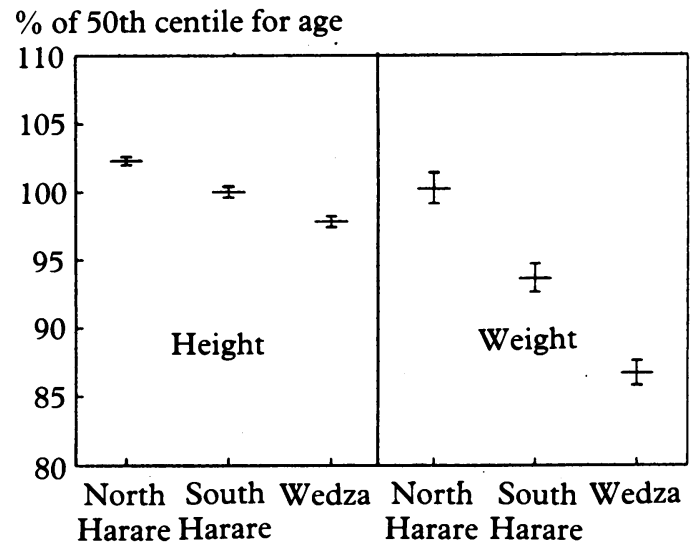

seen in white but not black children. In northern Harare white children with reversible airways obstruction had a male:female ratio of $2 \cdot 1$ but black children only $1 \cdot 1$ ( 1.0 for black children in the three study areas combined).

\section{NON-PARTICIPANTS}

Information about the children who were on the registers of the classes taking part in the study but who were excluaed from the analysis is given in table 1 . In northern Harare, where parental permission to participate in the study was sought, six children were said by the parents to be asthmatic. Four were refused permission to participate for this reason; the other two, both of whom were receiving regular

Table 1 Eligible children excluded from the analysis

\begin{tabular}{lrrr}
\hline Reason & $\begin{array}{l}\text { Northern } \\
\text { Harare }\end{array}$ & $\begin{array}{l}\text { Southern } \\
\text { Harare }\end{array}$ & Wedza \\
\hline Absent & 4 & 8 & 27 \\
$\quad$ No information & 14 & 12 & 7 \\
$\quad$ Not asthma & 0 & 4 & 4 \\
$\begin{array}{l}\text { Unfit to run } \\
\text { Unable to use } \\
\text { peak flow meter }\end{array}$ & 7 & 2 & 1 \\
$\begin{array}{l}\text { Run not completed } \\
\text { Permission withheld }\end{array}$ & 2 & 4 & 1 \\
$\quad$ Asthma & 4 & 0 & 0 \\
$\quad$ Other reason & 20 & 0 & 0 \\
$\quad$ & & & \\
Total excluded & 51 & 30 & 40 \\
$\quad$ Total included & 726 & 642 & 687 \\
\hline
\end{tabular}

prophylactic treatment, participated but showed no evidence of reversible airways obstruction and were counted as normal for the purposes of the study. The possibility that children in southern Harare or Wedza were having anti-asthma treatment at the time of the study cannot be excluded completely but is highly unlikely under local circumstances. No child in Wedza and only one in southern Harare was known by the teacher to be asthmatic.

None of the children for whom a cause of absence from school became known had been absent because of an acute respiratory illness and presumably therefore none had been absent as a result of asthma.

\section{NUTRITIONAL STATE}

Data on the nutritional state of the study groups (expressed as mean percentage of 50th centile height and weight for age, with $95 \%$ confidence intervals) are given in table 2 and shown in figure 2. Neither variable showed a significant difference between white and black children in northern Harare. Both height and weight were, however, significantly lower for children in southern Harare and significantly lower still for those in Wedza. The mean weight for age of the Wedża children $(86.7 \%$ of the 50th centile) corresponds approximately to the 10th percentile in the Tanner-Whitehouse standards.

There were no significant differences between the mean height and weight for age of children with and without evidence of reversible airways obstruction, whether the analysis was conducted for all children or for each of the three study groups.

\section{Discussion}

The six minute free running screening test for exercise induced bronchoconstriction was chosen because it can be used to study a large number of children in a short time. Free running is accepted as the form of exercise which most reliably provokes bronchoconstriction in susceptible individuals. ${ }^{16}{ }^{17} \mathrm{We}$ were not able to document the adequacy of the exercise challenge by heart rate monitoring, nor did we measure the distance covered. We are confident, however, that the children in the rural sample on average ran further in the six minutes than the children in the urban samples.

This study shows striking differences in prevalence of objectively demonstrated reversible airways obstruction between three groups of children living in different environments in a developing country. The study was conducted over only three weeks, which minimised any confounding effect of seasonal changes in prevalence. The altitude and also the mean temperature and humidity during the study period were similar in Harare and Wedza.

The identical prevalence of reversible airways obstruction in two ethnic groups living in the same environment (white and black children in northern Harare) strongly supports the suggestion that environmental factors are of predominant importance in determining the 
Table 2 Indicators of nutritional state

\begin{tabular}{|c|c|c|}
\hline & \multicolumn{2}{|c|}{ Mean $(95 \%$ CI)\% of 50 th percentile } \\
\hline & height & weight \\
\hline $\begin{array}{l}\text { Northern Harare } \\
\text { (white children) } \\
\text { (black children) }\end{array}$ & $\begin{array}{l}102 \cdot 9(102 \cdot 3-103 \cdot 6) \\
102 \cdot 1(101 \cdot 7-102 \cdot 5)\end{array}$ & $\begin{array}{l}100 \cdot 8(99 \cdot 8-102 \cdot 9) \\
100 \cdot 0(98 \cdot 6-101 \cdot 4)\end{array}$ \\
\hline $\begin{array}{l}\text { Southern Harare } \\
\text { (black children) } \\
\text { Wedza } \\
\text { (black children) }\end{array}$ & $\begin{array}{c}100 \cdot 0(99 \cdot 6-100 \cdot 4) \\
97.8(97 \cdot 4-98 \cdot 2)\end{array}$ & $\begin{array}{l}93 \cdot 6(92 \cdot 6-94 \cdot 7) \\
86 \cdot 7(85 \cdot 8-87 \cdot 6)\end{array}$ \\
\hline
\end{tabular}

prevalence of asthma in a given population. The prevalences of reversible airways obstruction in southern Harare and Wedza in this study are strikingly similar to the prevalences among urban and rural Xhosa children in the study by Van Niekerk et al in South Africa, which had a similar design ${ }^{7}(3 \cdot 2 \%$ in urban Guguletu, $0 \cdot 15 \%$ in rural Transkei).

The male preponderance usually found among children with reversible airways obstruction in developed countries was found in the white children but not in the black children in our study. The latter finding is also in agreement with that of Van Niekerk?

There was no significant difference in height or weight between black and white children in northern Harare. Children in southern Harare were significantly shorter and lighter for their age than in northern Harare, and children in Wedza were shorter and lighter still. The differences in nutritional state of the three study groups correspond to their socioeconomic differences. They also correspond to the differences in the observed prevalence of reversible airways obstruction, poorer nutrition being associated with a lower prevalence of reversible airways obstruction.

The prevalence of childhood asthma appears to have increased in industrialised countries in the last 20 years, ${ }^{1-5}$ and it varies widely between urban and rural environments in the developing world ${ }^{67}$ Several possible explanations for these differences have been advanced. Altered behaviour of immune mechanisms might result from a change in the pattern or prevalence of infectious disease; ${ }^{18}$ changes in lifestyle may cause changes in the pattern of exposure to various known or potential allergens-such as the house dust mite, ${ }^{19}$ food colourings and additives, and antibiotics and other medicines; changes in diet, such as alterations in breast feeding practices or patterns of salt consumption, ${ }^{20}$ may play a part; and a recent hypothesis is that the increasingly widespread use of antiasthma treatments, particularly beta ${ }_{2}$ agonists, might itself be contributing to the observed increase in morbidity and mortality from asthma. ${ }^{21}$

Our study was not designed to test any of these hypotheses directly. Infectious diseases in general are more common among rural than among urban children, and more common in the poorer than in the richer population in Harare. Among the rural children in our study, for example, at least one in 10 had active impetigo. In rural Zimbabwe schistosomiasis is widespread; $;^{22}$ rates of infestation with gastrointestinal helminths are generally low in most parts of the country but with geographically localised pockets of higher prevalence. ${ }^{23}$ The prevalence of parasitisation is likely to be lower in children in Harare but there are no published data on this point. In Zimbabwe, as elsewhere, average family size decreases with rising socioeconomic status; Strachan found a negative association between number of older siblings and prevalence of hay fever in British children born in 1958, suggesting the possibility that more frequent infections in early childhood might protect against the development of allergic disease. ${ }^{24}$

Urban children in Zimbabwe, like their contemporaries in Western societies, are now rather unlikely to reach the age of 5 without having received several courses of antibiotic treatment; this is not yet the case for rural Zimbabwean children. Antibiotics might be relevant either by reducing the extent of bacterial challenge to the immune system in childhood or, conceivably, by acting as inducers of hypersensitivity in their own right. The use of anti-asthma treatments in children in Zimbabwe is much less than in Britain-only six children in the northern Harare group were known by their teachers to have asthma, one in southern Harare, and none in Wedza. The use of beta ${ }_{2}$ agonists in urban Zimbabwean children is most unlikely to have been sufficiently widespread to have contributed to the differences in the prevalence of reversible airways obstruction in our study.

Typical housing conditions differ widely between our three study areas: large Western style houses in northern Harare, small (often crowded) breeze block houses in southern Harare, and thatched pole and dagga or brick huts in Wedza. Blankets are usually used for sleeping in all three areas but few rural children sleep on mattresses. Nearly all adult asthmatic patients attending an urban clinic in Zimbabwe show house dust mite sensitivity. ${ }^{12}$ Godfrey $^{6}$ found the house dust mite to be plentiful in rural homes in the Gambia, but factors such as ventilation, temperature, and humidity as well as the amount and nature of bedding and furnishings might affect the allergen content of the domestic atmosphere. Rural children in Zimbabwe undoubtedly spend less time in houses than do urban children, thus presumably reducing their exposure to the house dust mite. Urban children in Zimbabwe have far greater exposure than rural children to atmospheric pollution, notably automobile emissions, and to chemical additive in manufactured foods and drinks.

Most infants in both rural and urban Zimbabwe are breast fed but urban infants are more likely than rural infants to be fed wholly or partly with a cow's milk formula. There are no data on salt intake of rural and urban populations in Zimbabwe. Significantly higher mean urinary sodium:potassium ratios were found in town dwellers than in rural controls in the Kenyan Luo migration study. ${ }^{25}$

Childhood asthma should be added to the list of the so called "diseases of civilisation." The 
findings of this study add further to an increasing body of evidence that the prevalence of asthma is environmentally determined. We have shown large differences in prevalence between populations living in close geographical proximity; further studies are needed to try to relate these differences to specific factors in the environment. The possibility exists of identifying an environmental factor or factors whose avoidance might reduce the high prevalence of asthma currently found among the children of the industrialised world. The free running exercise test is a quick and convenient method of screening populations of children for the prevalence of bronchial hyperreactivity.

We thank the Secretaries for Health and Education of the We thank the Secretaries for Health and Education of the Government of Zimbabwe for their permission to conduct the
study, Maria Mhondo and Tsitsi Kusemamariwo for technical study, Maria Mhondo and Tsitsi Kusemamariwo for technical assistance, Rosie Todd for hospitality in Wedza, and Glaxo
Zimbabwe for financial support. We are grateful to Professor Anne Tattersfield for early discussions. Most of all we would like to thank the headmasters, staff, and pupils of Alfred Beit, Chamatendere, Chirodzo, Chisipite, Chitsere, Gandamasungo, Hallingbury, Mount St Mary's, St Augustine's, St John's, St cooperation with the study.

1 Fleming DM, Crombie DL. Prevalence of asthma and hay fever in England and Wales. BMJ 1987;294:279-83.

2 Sears MR, Beaglehole R. Asthma morbidity and mortality: New Zealand. J Allergy Clin Immunol 1987;80:383-8.

3 Evans R III, Mullally DI, Wilson RW, Gergan PJ, Rosenberg HM, Grauman JS, et al. National trends in the morbidity and mortality of asthma in the US. Chest 1987;91:65-73S

4 Burr M, Butland B, King S, Vaughan-Williams E. Changes in asthma prevalence: two surveys 15 years apart. Arch Dis Childhood 1989;64:1452-6.

5 Burney PG, Chinn S, Rona RJ. Has the prevalence of asthma increased in children? Evidence from the national study of health and growth 1973-86. BMJ 1990;300:1306-10.
6 Godfrey RC. Asthma and IgE levels in urban and rural communities in the Gambia. Clin Allergy 1975;5:201-7.

7 Van Niekerk CH, Weinberg EG, Shore HC, Heese H de V, Van Schalkwyk DJ. Prevalence of asthma: a comparative study of urban and rural Xhosa children. Clin Allergy 1979;9:319-24.

8 Waite DA, Eyles EF, Tarkin SL, O'Donnell TV. Asthma prevalence in Tokelauan children in two environments. Clin Allergy 1980;10:71-5.

9 Scadding JG. The definition of asthma: general introduction In: Porter R, Birch J, eds. Identification of asthma. London Churchill Livingstone, 1971:13-20. (CIBA Foundation symposium 38).

10 Anderson SD, Silverman M, Konig P, Godfrey S. Exerciseinduced asthma. $\mathrm{Br} J$ Dis Chest 1975;69:1-39.

11 Tsanakas JN, Milner RDG, Bannister OM, Boon AW. Free running asthma screening test. Arch Dis Childhood 1988, 63:261-5.

12 Cookson J, Makoni G. Seasonal asthma and the house dust mite in tropical Africa. Clin Allergy 1975;5:375-80.

13 Godfrey S, Kamburoff P, Nairn J. Spirometry, lung volumes and airway resistance in normal children aged five to eighteen years. Br J Dis Chest 1970;64:15-24.

14 Ryan B, Joiner B, Ryan T. Minitab handbook. 2nd ed. Boston, Mass: PWS Kent Publishing, 1985

15 Armitage P, Berry G. Statistical methods in medical research. 2nd ed. Oxford: Blackwell, 1985:117.

16 Anderson S, Connolly N, Godfrey S. Comparison of bronchoconstriction induced by cycling and running. Thorax 1971;26:396-401.

17 Shapiro G, Pierson W, Furukawa C, Bierman W. A comparison of the effectiveness of free running and treadmill exercise for assessing exercise induced bronchospasm in clinical practice. J Allergy Clin Immunol 1979;64:609-11.

18 Anonymous. IgE, parasites and allergy [editorial]. Lancet 1976;i:894.

19 Sporik R, Holgate ST, Platts-Mills TAE, Cogswell JJ. Exposure to house-dust mite allergen $(\operatorname{Der} \mathrm{pI})$ and the development of asthma in childhood. A prospective study. N Engl J Med 1990;323:502-7.

20 Burney PG. The causes of asthma-does salt potentiate bronchial reactivity? JR Soc Med 1987;80:364-7.

21 Page CP. One explanation of the asthma paradox: inhibition of natural anti-inflammatory mechanism by $\beta_{2}$ agonists. Lancet 1991;337:717-20.

22 Taylor $P$, Makura $O$. Prevalence and distribution of schistosomiasis in Zimbabwe. Ann Trop Med Parasitol 1985;79:287-99.

23 Chandiwana SK. The problem and control of gastrointestinal helminthiasis in Zimbabwe. Eur J Epidemiol 1989;5:507-15.

24 Strachan DP. Hay fever, hygiene and household size. $B M J$ 1989;299:1259-60.

25 Poulter NR, Khaw KT, Hopwood BE, Mugambi J, Peart WS, Rose G, et al. The Kenyan Luo migration study: observations on the initiation of a rise in blood pressure. BMJ 1990;300:967-72. 